\title{
Terminología académica en urología y riesgos profesionales: aviso a responsables
}

\author{
Vela Navarrete R. \\ Cátedra y Servicio de Urología Fundación Jiménez Díaz. Academia Europea de Urología.
}

Actas Urol Esp. 2008;32(2):167-168

$\mathrm{E}^{\mathrm{n}}$ n la pasada reunión de la Academia Europea de Urología, cuyos objetivos formativos y profesionales son muy variados, en presencia del Secretario General de la Asociación Europea de Urología el Profesor Abrahamsson, volvió a suscitarse el riesgo que puede tener para nuestra especialidad el uso, académicamente correcto, de dos especialidades profesionales de manera conjunta o emparejada. Uno de los primeros ejemplos se refiere al término de uro-ginecologia que se prodigó en exceso al principio de los setenta. En algún momento también se propuso el término de urologia geriátrica, que afortunadamente sólo prosperó en ambientes reducidos. Pero el motivo de la discusión se refirió al término de urología oncológica o uro-oncología. Repetimos que desde el punto de vista académico no hay ningún motivo para rechazar esta combinación terminológica. Sin embargo, si pueden transmitirse algunos reparos desde el punto de vista profesional; existen consecuencias potencialmente negativas para la actividad urológica e incluso facilitar la segregación de algunos temas en favor de otras especialidades emparejadas. Se citaron algunos ejemplos que merece la pena recordar, ya superados los efectos del famoso combinado de urologia pediátrica, que felizmente, pero no sin grandes esfuerzo, parece haber encontrado una solución aceptable en muchos países.

¿Por qué urología femenina o urología de la mujer en vez de urología ginecológica (Female Urology)? En opinión de algunos, en el momento en que este término comenzó a utilizarse, los ginecólogos se interesaron por un tema que hasta entonces tenían un poco distante, asumiendo que los expertos en los trastornos urinarios y más en concreto, en la incontinencia, eran los urólogos. Naturalmente esta situación no era similar en todos los países europeos y en algunos la tradición había puesto en manos de los gine- cólogos la incontinencia femenina más que en el proyecto asistencial de los urólogos. En cualquier caso, algunos cambios de estrategia asistencial sugieren que este nuevo término pareció obligar a los ginecólogos a tomar conciencia de un protagonismo que habian soslayado. La realidad actual es que esta colaboración, en el campo concreto de la incontinencia de esfuerzo, se ha convertido en un compromiso habitual, sin duda en beneficio de los pacientes, sobre todo los casos complejos en los que la reconstrucción del suelo pélvico es obligada. El esfuerzo del urólogo, clínico, quirúrgico y farmacológico, parece haberse limitado en los últimos años a favor de un mayor entusiasmo y presencia efectiva en este campo por parte de los ginecólogos.

Se han publicado varios libros con el título de urología geriátrica o geriatría urológica (Geriatric Urology) en diferentes idiomas. No parece que esta iniciativa haya despertado ninguna reacción crítica. El tema del varón añoso constituye uno de los campos de acción asistencial más importantes del urólogo para los años venideros. La misma Organización Mundial de la Salud con su proyecto sobre envejecimiento activo (active ageing) fue distanciándose del uso del término geriátrico, referido a un estado más que a un proceso. Más recientemente el término de longevidad va ganando adeptos por su relieve más positivo que el de envejecimiento. En este contexto y orillando cualquier referencia a la edad, los urólogos están escribiendo libros sobre la "salud del varón", ampliando su dedicación e interés sobre todo por el varón añoso que es la fuente fundamental de sus actividades por sus frecuentes patologías (HBP, cáncer de próstata, androgenodeficiencia, disfunción eréctil, incontinencia, etc.) y cada día reclamando más una visión integral del individuoy no parcialidades somáticas o soluciones quirúrgicas exclusivas del en otro tiempo 
autocalificado cirujano urólogo, una actitud que incluye el riesgo de que como se pierda el procedimiento, por cualquier avance alternativo, menos invasivo, se perderá también el paciente y la patología correspondiente. En definitiva, parece razonable insistir en nuestros escritos y actividades sobre la salud del varón, la salud del varón añoso, urología y longevidad, o términos similares, pero nunca haciendo coincidir dos términos de representatividad profesional reconocida, aunque sólo sea a nivel hospitalario, como la Geriatria.

¿Por qué no urología oncológica o oncología urológica (Oncologic Urology or Urologic Oncology)?. Es este emparejamiento el que motivó las discusiones más importantes. De hecho en los últimos meses han aparecido varios programas en el que se incluyen ambos títulos y precisamente promovidos por los urólogos. La Asociación Europea de Urología tiene una sección bajo el título de "Society of Oncological Urology (ESOU) y nosotros un grupo de trabajo de "Urologia Oncológica". En el discurso de despedida de nuestro pasado Secretario General, Prof. Frans Debruyne cuya traducción está publicada en Actas Urológicas Españolas, también se recurrió a esta combinación de términos con amplia generosidad. Sin embargo, desde una perspectiva crítica, sostenida por pasadas experiencias, la propuesta contraria consiste en referirse, tanto en programas de Congresos o Cursos como en libros o publicaciones, a cáncer urogenital, cáncer urológicos, o tumores urogenitales o algún otro término más brillante que se le ocurra a las nuevas generaciones de urólogos. De hecho, puede constatarse que en los libros de texto urológicos tradicionales pocas veces se combinan los términos de uro-oncología refiriéndose muchas más veces el de cánceres urogenitales o cánceres urológicos. Tengo presente en este momento dos libros con este título: "Urologic Cancer; M. Ernstoff et al. Blackwell 1997, Cáncer Urológico M. Srougi Sao Paulo 1990 y otros más, confirmando que esta tendencia al emparejamiento es más reciente, a partir del 2000.

Ciertamente, nadie conoce mejor la historia natural de los cánceres urológicos que el urólogo. La mayoría de ellos recibieron tratamiento quirúrgico inicial pero hay circunstancias en las que necesariamente es preciso recurrir a quimioterapia, sin duda mejor conocida por el oncólogo clínico, o a radioterapia, mejor conocida por el radiote- rapéuta, o la combinación de ambos procedimientos. La Oncologia Médica, una especialidad hospitalaria reconocida por el Sistema MIR a nivel europeo e internacional, como la de Radioterapia, han progresado de manera extraordinaria en los últimos años y emergen como alternativas eficaces frente a cirugia en tumores primarios y, por supuesto, como adyuvancia en otras muchas circunstancias. La colaboración con estas especialidades es cada día más necesaria, incluso obligada, y cada día en mayor número de casos. Se favorece "sesiones conjuntas" para definir estrategias individuales en tumores concretos y en casos concretos. Todo ello en beneficio del enfermo.

El riesgo profesional aparece cuando se propone "institucionalizar" esta colaboración en forma de "unidades asistenciales", sin duda inicialmente multioperativas y con presencia de variados especialistas, pero finalmente bajo el control oncológico. Sorprende a los entusiastas de estas propuestas que esta colaboración no sea tan común y ordinaria incluso entre expertos oncológicos de variadas especialidades como oncólogos clínicos, radioterapeutas y hematólogos.

Es, por lo tanto, razonable desde la perspectiva moderna, que incluye la demanda obligada de que en muchos procesos tumorales malignos sea necesaria la colaboración de varios expertos, que el urólogo mantenga la coordinación del proyecto terapéutico. Sin embargo, al menos por ahora, aunque estos enfermos son inicialmente urológicos, el urólogo entiende, por las razones que sean, o simplemente porque ya no considera que son candidatos de nuevos procedimientos quirúrgicos, que pasen a otros especialistas y además lo manifiesta y proclama. Es muy posible, de este modo, que termine por perder, primero un grupo de enfermos concretos, y finalmente la patología en cuestión. Insistimos, una vez más, en que el urólogo no es sólo un experto en procedimientos quirúrgicos sino un responsable asistencial de patologias concretas en sus variadas vertientes médicas y quirúrgicas. Acomodarse con inteligencia al progreso asistencial es la clave, más que delegar compromisos iniciando la huida con terminología equívocas y lo que es peor favoreciéndolas.

Correspondecia autor: Prof. R. Vela Navarrete Servicio de Urología. Fundación Jiménez Díaz Avda de los Reyes Católicos, 2 - 28040 Madrid Tel.: 915504800

E-mail autor: rvelan@telefonica.net Información artículo: Editorial 